\title{
Determinants of Sleepiness among Pupils in Kanto District of Japan
}

\author{
Jun Kohyama \\ Department of Paediatrics, Tokyo Bay Urayasu Ichikawa Medical Centre, Urayasu, Japan \\ Email:info@j-kohyama.jp
}

How to cite this paper: Kohyama, J. (2021) Determinants of Sleepiness among Pupils in Kanto District of Japan. Journal of Behavioral and Brain Science, 11, 97-106. https://doi.org/10.4236/jbbs.2021.115008

Received: April 1, 2021

Accepted: May 10, 2021

Published: May 13, 2021

Copyright (c) 2021 by author(s) and Scientific Research Publishing Inc. This work is licensed under the Creative Commons Attribution International License (CC BY 4.0).

http://creativecommons.org/licenses/by/4.0/

\begin{abstract}
Backgrounds: Sleepiness is reported to predict sleep quality, academic performance and self-regulation. This study aimed to discover determinants of sleepiness. Methods: On 2722 questionnaires obtained from pupils in grades $5-12$ in the Kanto district of Japan, lifestyle habits associated with sleepiness were analyzed using a multivariable logistic regression model. Results: The rate of sleepy pupils (who feel sleepy during class as often and always) increased from elementary school (6.3\%) to senior high school (42.4\%) via junior high school (17.1\%). Higher grade (adjusted odds ratio [OR], 1.28; 95\% confidence interval [CI], $1.21-1.37 ; \mathrm{p}<0.001)$, later bedtime before school day (OR, 1.41; CI, $1.26-1.57 ; \mathrm{p}<0.001$ ), longer non-school day screen time (OR, 1.27; CI, $1.16-1.40 ; \mathrm{p}<0.001$ ), poor self-reported academic performance (OR, 1.41; CI, $1.24-1.60 ; \mathrm{p}<0.001)$, skipping breakfast (OR, 1.18; CI, $1.01-1.39 ; \mathrm{p}=0.041$ ), earlier wake time on school day (OR, 0.84; CI, 0.71 $0.98 ; \mathrm{p}=0.026)$, and higher after-school (OR, 1.03; CI, $1.02-1.04 ; \mathrm{p}<0.001)$ and physical activities (OR, 1.06; CL, $1.03-1.10$; $\mathrm{p}<0.001$ ) were independently associated with sleepy pupils. Conclusions: To reduce adolescents' sleepiness in the Kanto district of Japan, we recommend them to have adequate waking time, and to avoid late bedtime, breakfast skipping, excessive screen time, after-school activity, and physical activity. Further prospective studies are needed to confirm involvements of these recommended factors in sleepiness and both physical and mental health outcomes.
\end{abstract}

\section{Keywords}

Academic Performance, After-School Activity, Bedtime, Breakfast Skipping, Physical Activity, Screen Time, Wake Time

\section{Introduction}

Sleep quality and sleep duration represent two separate sleep domains [1]. Both 
components must be needed to satisfy sleep need, and sleep need is not satisfied in insufficient sleep syndrome. However, in the diagnostic criteria of insufficient sleep syndrome, the term "sleep quality" was not found [2]. Different from quantifiable components of sleep such as number of awakenings at night, sleep latency, and sleep duration, sleep quality includes largely subjective indices of sleep, such as depth of sleep, how well rested one feels upon awakening, and general satisfaction with sleep [3]. Assessment of sleep quality is an old but relevant issue to be discussed. Although relatively old manuscripts, the association between poorer sleep quality and increased sleepiness was reported [4] [5], and a predictable pattern of correlations between sleepiness and sleep quality was demonstrated [3]. However, interestingly, a similar pattern was not found between sleepiness and sleep quantity [3]. Sleepiness is assumed to be one of candidates to predict sleep quality.

Dewald et al. examined the associations among sleep quality (16 studies, $\mathrm{N}=$ 13,631 ), sleep duration (17 studies, $\mathrm{N}=15,199$ ), sleepiness (17 studies, $\mathrm{N}=$ 19,530 ), and school performance in three separate meta-analyses including influential factors (e.g., gender, age, parameter assessment) as moderators [1]. Though all three sleep variables were significantly but modestly related to school performance, sleepiness showed the strongest relation to school performance ( $r$ $=-0.133)$, followed by sleep quality $(r=0.096)$ and sleep duration $(r=0.069)$. Cohen-Zion and Shiloh [6] investigated the effects of sleep duration, chronotype, and sleepiness on day-to-day executive abilities and academic performance (AP) in a healthy adolescent sample. They found that the strongest predictors of impaired daily executive capacities are evening chronotype and degree of sleepiness. In association with sleep quality and daytime functioning, we might pay more attention to sleepiness than sleep duration.

Moreover, daytime sleepiness is also known as one of the stronger predictors of poor self-regulation than short nighttime sleep duration among adolescents [7]. Self-regulation is the "act of managing cognition and emotion to enable goal directed actions such as organizing behavior, controlling impulses, and solving problems constructively" [8]. Since self-regulation in adolescents contributes to a range of positive health and functioning outcomes that have potential longterm implications [7], more attention should be paid to sleepiness in association with not only sleep quality and AP but also a wider range of long-term brain functions. The current study aimed to discover determinants of sleepiness to deepen our understanding of sleep quality.

\section{Methods}

The current study was part of a survey conducted between October 2016 and November 2018 to determine mutual associations among lifestyle habits and to clarify associations of lifestyle habits with pupils' health and AP. Details of the survey have been described elsewhere [9].

The questionnaire (Table 1) was original, drawn up by taking queries from 
Table 1. Questionnaire.

\begin{tabular}{|c|c|}
\hline Queries & Choices for answer \\
\hline Please mark your grade. & $\begin{array}{l}\text { Elementary school (grade 5, 6), Junior high school (grade 1, 2, 3), High school (grade } \\
1,2,3 \text { ) }\end{array}$ \\
\hline Please mark your gender. & Gender (male, female) \\
\hline Please describe your height and weight. & Height $(\mathrm{cm})$, Weight $(\mathrm{kg})$ \\
\hline Please mark your bed time before school days. & $\begin{array}{l}\text { 1. }<8 \mathrm{PM}, 2.8 \mathrm{PM}-9 \mathrm{PM}, 3.9 \mathrm{PM}-10 \mathrm{PM}, 4.10 \mathrm{PM}-11 \mathrm{PM}, 5.11 \mathrm{PM}-12 \mathrm{AM}, \\
\text { 6. } 12 \mathrm{AM}-1 \mathrm{AM}, 7.1 \mathrm{AM}-2 \mathrm{AM}, 8.2 \mathrm{AM}-3 \mathrm{AM} \text { or } 9 .>3 \mathrm{AM}\end{array}$ \\
\hline Please mark your bed time before non-school days. & $\begin{array}{l}\text { 1. }<8 \mathrm{PM}, 2.8 \mathrm{PM}-9 \mathrm{PM}, 3.9 \mathrm{PM}-10 \mathrm{PM}, 4.10 \mathrm{PM}-11 \mathrm{PM}, 5.11 \mathrm{PM}-12 \mathrm{AM}, \\
\text { 6. } 12 \mathrm{AM}-1 \mathrm{AM}, 7.1 \mathrm{AM}-2 \mathrm{AM}, 8.2 \mathrm{AM}-3 \mathrm{AM} \text { or } 9 .>3 \mathrm{AM}\end{array}$ \\
\hline Please mark your wake time on school days. & $\begin{array}{l}\text { 1. }<5 \mathrm{AM}, 2.5 \mathrm{AM}-6 \mathrm{AM}, 3.6 \mathrm{AM}-7 \mathrm{AM}, 4.7 \mathrm{AM}-8 \mathrm{AM}, 5.8 \mathrm{AM}-9 \mathrm{AM}, \\
\text { 6. } 9 \mathrm{AM}-10 \mathrm{AM}, 7.10 \mathrm{AM}-11 \mathrm{AM}, 8.11 \mathrm{AM}-12 \mathrm{PM} \text { or } 9 .>12 \mathrm{PM}\end{array}$ \\
\hline Please mark you wake time on non-school days. & $\begin{array}{l}\text { 1. }<5 \mathrm{AM}, 2.5 \mathrm{AM}-6 \mathrm{AM}, 3.6 \mathrm{AM}-7 \mathrm{AM}, 4.7 \mathrm{AM}-8 \mathrm{AM}, 5.8 \mathrm{AM}-9 \mathrm{AM}, \\
\text { 6. } 9 \mathrm{AM}-10 \mathrm{AM}, 7.10 \mathrm{AM}-11 \mathrm{AM}, 8.11 \mathrm{AM}-12 \mathrm{PM} \text { or } 9 .>12 \mathrm{PM}\end{array}$ \\
\hline Please mark the frequency you feel sleepy during class. & 1. never, 2. sometimes, 3. often or 4. always \\
\hline Please mark your frequency of eating breakfast. & 1. always, 2. often, 3. sometimes or 4. never \\
\hline Please mark your frequency of defecation. & 1. every day, 2. every other day, 3 . once every two to three days, 4 . twice a week or less \\
\hline Please mark the time you usually eat dinner. & $\begin{array}{l}\text { 1. around } 6 \mathrm{PM}, 2 \text {. around } 7 \mathrm{PM}, 3 \text {. around } 8 \mathrm{PM}, 4 \text {. around } 9 \mathrm{PM}, 5 \text {. around } 10 \mathrm{PM} \text {, } \\
\text { 6. around } 11 \mathrm{PM}, 7 \text {, later than } 11 \mathrm{PM} \text { or } 8 \text {. not determined }\end{array}$ \\
\hline Do you participate in any kinds of after-school activity? & 1. Yes, 2. No \\
\hline $\begin{array}{l}\text { If yes, please mark your frequency of participating i } \\
\text { after-school activity. }\end{array}$ & $\begin{array}{l}\text { 1. once a week, 2. twice a week, 3. three times a week, } 4 \text {. four times a week, } \\
\text { 5. five times a week, } 6 \text {. six times a week or } 7 \text {. every day. }\end{array}$ \\
\hline
\end{tabular}

How many days a week do you perform habitual exercise 0. none, 1. one day per week, 2. two days per week, 3. three days per week, 4. four except for school lessons? days per week, 5. five days per week, 6. six days per week or 7. seven days per week

How long do you use various media devices (television, On a school day.

video, video game, digital versatile disc, computer, tablet, 1. $<2$ hours, $2.2-4$ hours, $3.4-6$ hours, $4.6-8$ hours or 5.8 hours or more.

mobile [cell] phone, smart phone) in a day? Please answer

separately on school days and non-school days.

On a non-school day.

1. $<2$ hours, 2. $2-4$ hours, $3.4-6$ hours, $4.6-8$ hours or 5.8 hours or more.

Please mark the best choice for your overall academic 1. very good, 2. good, 3. not good or 4. poor.

performance.

the Japan Society of School Health [10] into consideration. It was delivered to pupils in grades 5 to 12 by their school teacher. A letter was also provided to assure pupils that their responses would be treated as anonymous and confidential and that participation was voluntary. Written consent signed by a guardian and completed questionnaires were collected by teachers and sent to the author. Of the 4208 questionnaires collected from 28 public schools ( 15 elementary schools [ESs], eight junior high schools [JHSs], and five senior high schools [SHSs]) in the Kanto district, Japan, 2722 indicated the students' agreement to participate in the study and had complete answers to all required questions. No participant was overlapped.

The questionnaires included basic questions about school grade, gender, and 
self-reported body weight and height to determine body mass index (BMI). Bedtime scores before school day and non-school day, and wake time scores on school day and non-school day were calculated using the following representative times for each of the nine categories: 7:30 PM, 8:30 PM, 9:30 PM, 10:30 PM, 11:30 PM, 12:30 AM, 1:30 AM, 2:30 AM, and 3:30 AM for bedtimes, and 4:30 AM, 5:30 AM, 6:30 AM, 7:30 AM, 8:30 AM, 9:30 AM, 10:30 AM, 11:30 AM, and 12:30 PM for wake times. The response on sleepiness was expressed as sleepiness score. The hours of after-school activity per week (after-school activity score) were taken as the product of the frequency and duration of activities. The questionnaire did not limit after-school activity to academic activity. Physical activity score was defined by the number of days per week engaged in physical activity. A dinner regularity score of 1 was assigned to the choice of 1 to 7 designated regular dinner, and a dinner regularity score of 2 denoted irregular dinner (the last choice of 8). The responses on breakfast and defecation were expressed as skipping breakfast score and defecation score, respectively. Screen time on school days (school-day screen time score) and non-school days (non-school day screen time score) was asked separately. The responses on self-reported AP made up the self-reported AP score. BMI, calculated from body weight and height, varied by age and gender [9], and thus BMI values were standardised by grade and gender.

Lifestyle habits associated with sleepiness were analyzed using a multivariable logistic regression model. Since sleepiness scores were defined by the frequency pupils feel sleepy during class (SL1: never; SL2: sometimes; SL3: often; SL4: always), sleepy pupils were defined as those with SL3 and SL4. Assuming that the last grade of ES, JHS and SHS were facing huge pressure to advance to the next level education, correlation coefficient between sleepiness and self-reported AP of each grade might be altered. Then, these values were calculated and their differences between the adjacent grades was assessed. Grade, gender (male was numbered as one and female as two), after-school activity score, physical activity score, dinner irregularity score, skipping breakfast score, defecation score, schoolday screen time score, non-school day screen time score, self-reported AP score, and standardised BMI were covariate factors adjusted on the multivariable logistic regression model. This study was approved by the committee for medical research ethics of our institute (no. 199).

\section{Results}

Figure 1 shows the distribution of each sleepiness score. The highest category was SL2, except for male ES pupils, whose highest category was SL1. The rate of sleepy pupils (SL3 + SL4) among all the subjects was 19.9\%, and the rate increased from ES (6.3\%) to SHS (42.4\%) via JHS (17.1\%).

Correlation coefficient of each grade from 5 to 12 was $0.09,0.06,0.09,0.10$, $0.18,0.20,0.18$, and 0.24 , respectively. There were no significant differences of these values between the adjacent grades. 

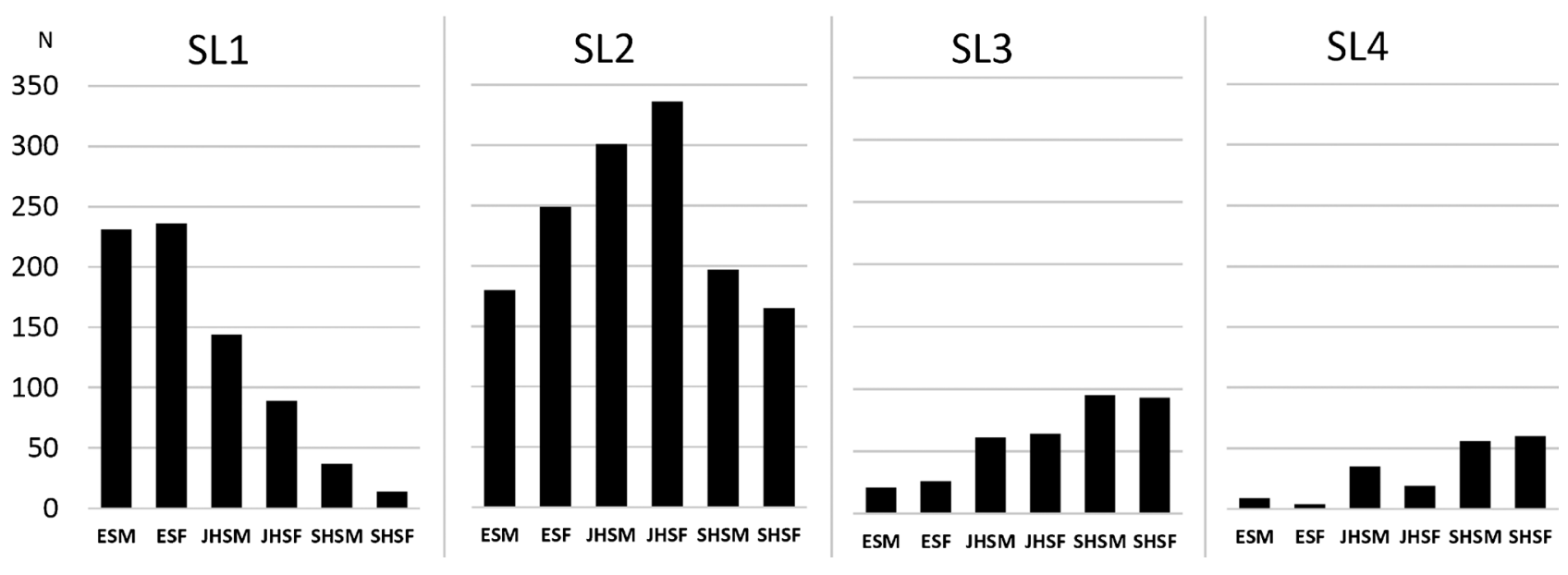

Frequency pupils feel sleepy during class: SL1: never; SL2: sometimes; SL3: often; SL4: always. ESM; elementary school male pupils, ESF; elementary school female pupils, JHSM; junior high school male pupils, JHSF; junior high school female pupils, SHSM; senior high school male pupils, SHSF; senior high school female pupils. N; number of pupils.

Figure 1. Number of pupils with each sleepiness score.

Table 2. Variables obtained for the optimised fitness model for sleepy pupils obtained by stepwise procedure of multivariable logistic regression analysis.

\begin{tabular}{cccccc}
\hline Variables & $\begin{array}{c}\text { Partial } \\
\text { regression } \\
\text { coefficient (B) }\end{array}$ & SE & $\begin{array}{c}\text { Wald } \\
\chi^{2}\end{array}$ & OR (95\% CI) & P value \\
\hline Grade & 0.25 & 0.03 & 62.09 & $1.28(1.21-1.37)$ & $<0.000000000001$ \\
Bedtime score before school day & 0.34 & 0.06 & 37.11 & $1.41(1.26-1.57)$ & 0.00000000011 \\
Non-school day screen time score & 0.24 & 0.05 & 25.30 & $1.27(1.16-1.40)$ & 0.000000049 \\
Self-reported academic performance score & 0.34 & 0.07 & 26.64 & $1.41(1.24-1.60)$ & 0.000000025 \\
Skipping breakfast score & 0.17 & 0.08 & 4.18 & $1.18(1.01-1.39)$ & 0.041 \\
Wake time score on school day & -0.18 & 0.08 & 4.92 & $0.84(0.71-0.98)$ & 0.026 \\
After-school activity score & 0.03 & 0.01 & 20.42 & $1.03(1.02-1.04)$ & 0.0000062 \\
Physical activity score & 0.06 & 0.02 & 11.28 & $1.06(1.03-1.10)$ & 0.00078 \\
Standardised BMI & 0.09 & 0.05 & 3.18 & $1.09(0.99-1.21)$ & 0.075 \\
constant & -6.65 & 0.40 & & & \\
\hline
\end{tabular}

SE, standard error; OR, adjusted odds ratio; CI, confidence interval.

Table 2 shows variables obtained for the optimised fitness model for sleepy pupils obtained by stepwise procedure of multivariable logistic regression analysis. Among these coefficients, grade (adjusted odds ratio [OR], 1.28; 95\% CI, 1.21 - 1.37; $\mathrm{p}<0.001$ ), bedtime score before school day (OR, 1.41; CI, 1.26 - 1.57; $\mathrm{p}<0.001$ ), non-school day screen time score (OR, 1.27; CI, $1.16-1.40 ; \mathrm{p}<$ $0.001)$, AP score (OR, 1.41; CI, $1.24-1.60 ; \mathrm{p}<0.001)$, skipping breakfast score (OR, 1.18; CI, $1.01-1.39 ; \mathrm{p}=0.041)$, wake time score on school day (OR, 0.84; CI, $0.71-0.98 ; \mathrm{p}=0.026)$, after-school activity score (OR, 1.03; CI, $1.02-1.04 ; \mathrm{p}$ $<0.001$ ), and physical activity score (OR, 1.06; CL, $1.03-1.10 ; \mathrm{p}<0.001$ ) were independently associated with sleepy pupils (Table 2). The Akaike information 
criterion of this model (2264) was lower than a model obtained by all factors (2273) or that obtained by significant factors (2268).

\section{Discussion}

An increase of the rate of sleepiness with age was observed in Brazilian adolescents from 10 to 17 years [11]. A Korean study with a sample of 1457 schoolchildren aged 9 to 19 years also found the increase of the prevalence of daytime sleepiness as grade levels increased from the $5^{\text {th }}$ to $12^{\text {th }}$ grade [12]. The current study also observed a similar significant elevation of sleepiness rate with grade elevation through multivariable logistic regression analysis. The Korean study also found that $6.6 \%$ of the respondents admitted to daytime sleepiness being a major problem. A survey of 1413 Swedish children aged 6 to 11 years highlighted a $4 \%$ prevalence rate of daytime sleepiness [13]. However, the overall prevalence of excessive daytime sleepiness was reported to be $29.2 \%$ among Hong-Kong children aged 6 - 18 years [14], and 41.5\% of US adolescents aged 13 to 18 years reported feeling sleepy during the daytime [15]. The current results (the rate of sleepy pupils of 19.9\%) showed the medium figure among these studies. It should be noted that both articles reporting higher sleepiness rates were published in 2019 [14] [15]. The sleepiness rate among adolescents may be increasing recently. In addition, an involvement of academic pressure situations should also be noted for taking the rate of sleepiness into mind. Chen et al. [16] reported that the severity of fatigue, sleep quality, sleepiness, and depression among SHS pupils in Taiwan were significantly diminished in the group under less academic stress. Current study did not ask about the situation of academic pressure, and found no differences on correlation coefficients of sleepiness and AP between the adjacent grades. Furthermore, educational system is another factors presumably affect sleepiness of specific grade group.

The current study found that higher grade, later bedtime before school days and earlier wake time on school days, breakfast skipping, longer screen time on non-school days, poor AP, higher after-school activity, and physical activity were independently associated with sleepy pupils. A significant association between sleepy pupils and poor AP was consistent with previous reports. Later bedtimes are known to contribute to sleepiness during class [17], and longer screen time is known to contribute to sleepiness after awakening in the morning [18]. Irregular breakfast eating was reported to be associated with chronic sleepiness [19], and a significant relationship between regularity of breakfast timing and less sleepiness was shown [20].

In contrast to the present study, increased sleepiness was reported to be associated with fewer extracurricular activities in Canadian students [21]. However, consistent with the present study, students who belonged to athletic clubs and cultural clubs revealed significantly higher risks for falling asleep during classes [22]. Undesirably early morning arousal is reported to lead to impaired evening function with excessive sleepiness [23]. Consistent with the current result, slee- 
piness has been reported to be associated with athletes who are engaged in excessive physical activity [24] [25] [26]. An association between lower physical activity and daytime sleepiness was reported in $5^{\text {th }}$ - and $6^{\text {th }}$-grade (ages 10 - 12) boys in Japan; however, this study did not assess the association between higher physical activity and sleepiness [27].

There were some limitations to the current study. First, the study used a cross-sectional design and was unable to identify a causal relationship. Second, the questionnaire was not validated. However, it was made with reference to a questionnaire used in a national survey, the results of which have been used as the fundamental data for policymaking as well as for developing manuals on the proper lifestyle of children in Japan [10]. Third, although there were several standardised questionnaires that assess sleepiness, the currently used questionnaire for assessing sleepiness was extremely simple (i.e., only one question with four selections). It should be noted that test-retest reliability of the famous Epworth Sleepiness Scale has recently been reported to be poor [28]. Fourth, the responses to the questionnaire depended on self-reports without objective measurements. However, the mean BMI values obtained were similar to those of Japanese schoolchildren [10]. Fifth, the present study did not include demographic factors such as family composition, socioeconomic status, and parents' educational background. Finally, this study lacked age-related information, as the queries we referred to lacked information about age [10]. However, it should not be forgotten that age is an important biological factor.

Despite the above limitations, the current study demonstrated that sleepy pupils were associated with higher grade, later bedtime and earlier wake time on school days, breakfast skipping, longer screen time on non-school days, poor AP, and higher after-school and physical activities. It should be emphasised that sleepiness is one of the stronger predictors of poor self-regulation, and self-regulation in adolescents which contributes to a range of positive health and functioning outcomes that have potential long-term implications [6]. More attention should be paid to sleepiness in association with a wide range of long-term brain functions. In order to reduce adolescents' sleepiness and to support their healthy lives in the Kanto district of Japan, we recommend them to have adequate waking time, and to avoid late bedtime, breakfast skipping, excessive screen time, after-school activity, and physical activity. Further prospective studies controlling waking time, bedtime, breakfast, screen time, after-school activity, and physical activity, and assessing sleepiness and both physical and mental health outcomes are needed. It has remained to be discussed whether the current study on the determinants of sleepiness deepens our understanding of sleep quality.

\section{Conflicts of Interest}

The author declares no conflicts of interest regarding the publication of this paper. 


\section{References}

[1] Dewald, J.F., Meijer, A.M., Oort, F.J., Kerkhof, G.A. and Bögels, S.M. (2010) The Influence of Sleep Quality, Sleep Duration and Sleepiness on School Performance in Children and Adolescents: A Meta-Analytic Review. Sleep Medicine Reviews, 14, 179-189. https://doi.org/10.1016/j.smrv.2009.10.004

[2] American Academy of Sleep Medicine (2014) The International Classification of Sleep Disorders. 3rd Edition, American Academy of Sleep Medicine, Westchester.

[3] Pilcher, J.J., Ginter, D.R. and Sadowsky, B. (1997) Sleep Quality versus Sleep Quantity: Relationships between Sleep and Measures of Health, Well-Being and Sleepiness in College Students. Journal of Psychosomatic Research, 42, 583-596. https://doi.org/10.1016/S0022-3999(97)00004-4

[4] Lugaresi, E., Cirignotta, F., Zucconi, M., Mondini, S., Lenzi, P.L. and Coccagna, G. (1983) Good and Poor Sleepers: An Epidemiological Survey of the San Marino Population. In: Guilleminault, C. and Lugaresi, E., Eds., Sleep/ Wake Disorders: Natural History, Epidemiology and Long-Term Evolution, Raven Press, New York, 13-28.

[5] Hyyppä, M.T., Kronholm, E. and Mattlar, C.E. (1991) Mental Well-Being of Good Sleepers in a Random Population Sample. The British Journal of Medical Psychology, 64, 25-34. https://doi.org/10.1111/j.2044-8341.1991.tb01639.x

[6] Cohen-Zion, M. and Shiloh, E. (2018) Evening Chronotype and Sleepiness Predict Impairment in Executive Abilities and Academic Performance of Adolescents. Chronobiology International, 35, 137-145. https://doi.org/10.1080/07420528.2017.1387792

[7] Owens, J.A., Dearth-Wesley, T., Lewin, D., Gioia, G. and Whitaker, R.C. (2016) Self-Regulation and Sleep Duration, Sleepiness, and Chronotype in Adolescents. Pediatrics, 138, e20161406. https://doi.org/10.1542/peds.2016-1406

[8] Murray, D.W., Rosanbalm, K., Christopoulos, C. and Hamoudi, A. (2014) SelfRegulation and Toxic Stress: Foundations for Understanding Self-Regulation from an Applied Developmental Perspective. Office of Planning, Research and Evaluation, Administration for Children and Families, US Department of Health and $\mathrm{Hu}-$ man Services, Washington DC.

[9] Kohyama, J., Ono, M., Anzai, Y., Kishino, A., Tamanuki, K., Moriyama, K., Saito, Y., Emoto, R., Fuse, G. and Hatai, Y. (2020) Factors Associated with Sleep Duration among Pupils. Pediatrics International, 62, 716-724. https://doi.org/10.1111/ped.14178

[10] Japan Society of School Health (2018) Annual Reports on Health of Children Attending Elementary Schools and Junior High Schools in 2015-17. Japan Society of School Health, Tokyo.

[11] de Souza Vilela, T., Bittencourt, L.R., Tufik, S. and Moreira, G.A. (2016) Factors Influencing Excessive Daytime Sleepiness in Adolescents. Jornal de Pediatria, 92, 149155. https://doi.org/10.1016/j.jped.2015.05.006

[12] Yang, C.K., Kim, J.K., Patel, S.R. and Lee, J.H. (2005) Age-Related Changes in Sleep/ Wake Patterns among Korean Teenagers. Pediatrics, 115, 250-256. https://doi.org/10.1542/peds.2004-0815G

[13] Nevéus, T., Cnattingius, S., Olsson, U. and Hetta, J. (2001) Sleep Habits and Sleep Problems among a Community Sample of Schoolchildren. Acta Paediatrica, 90, 14501455. https://doi.org/10.1111/j.1651-2227.2001.tb01612.x

[14] Liu, Y., Zhang, J., Li, S.X., Chan, N.Y., Yu, M., Lam, S.P., Chan, J., Li, A.M. and Wing, Y.K. (2019) Excessive Daytime Sleepiness among Children and Adolescents: 
Prevalence, Correlates, and Pubertal Effects. Sleep Medicine, 53, 1-8. https://doi.org/10.1016/j.sleep.2018.08.028

[15] Kolla, B.P., He, J.P., Mansukhani, M.P., Kotagal, S., Frye, M.A. and Merikangas, K.R. (2019) Prevalence and Correlates of Hypersomnolence Symptoms in US Teens. Journal of the American Academy of Child and Adolescent Psychiatry, 58, 712-720. https://doi.org/10.1016/j.jaac.2018.09.435

[16] Chen, T.Y., Chou, Y.C., Tzeng, N.S., Chang, H.A., Kuo, S.C., Pan, P.Y., Yeh, Y.W., Yeh, C.B. and Mao, W.C. (2015) Effects of a Selective Educational System on Fatigue, Sleep Problems, Daytime Sleepiness, and Depression among Senior High School Adolescents in Taiwan. Neuropsychiatric Disease and Treatment, 11, 741-750. https://doi.org/10.2147/NDT.S77179

[17] Arakawa, M., Taira, K., Tanaka, H., Yamakawa, K., Toguchi, H., Kadekaru, H., Yamamoto, Y., Uezu, E. and Shirakawa, S. (2001) A Survey of Junior High School Students' Sleep Habit and Lifestyle in Okinawa. Psychiatry and Clinical Neurosciences, 55, 211-212. https://doi.org/10.1046/j.1440-1819.2001.00829.x

[18] Kojima, R., Sato, M., Akiyama, Y., Shinohara, R., Mizorogi, S., Suzuki, K., Yokomichi, H. and Yamagata, Z. (2019) Problematic Internet Use and Its Associations with Health-Related Symptoms and Lifestyle Habits among Rural Japanese Adolescents. Psychiatry and Clinical Neurosciences, 73, 20-26. https://doi.org/10.1111/pcn.12791

[19] Saarenpää-Heikkilä, O., Laippala, P. and Koivikko, M. (2001) Subjective Daytime Sleepiness and Its Predictors in Finnish Adolescents in an Interview Study. Acta Pædiatrica, 90, 552-557. https://doi.org/10.1111/j.1651-2227.2001.tb00797.x

[20] Nakade, M., Takeuchi, H., Kurotani, M. and Harada, T. (2009) Effects of Meal Habits and Alcohol/Cigarette Consumption on Morningness-Eveningness Preference and Sleep Habits by Japanese Female Students Aged 18-29. Journal of Physiological Anthropology, 28, 83-90. https://doi.org/10.2114/jpa2.28.83

[21] Gibson, E.S., Powles, A.C., Thabane, L., O’Brien, S., Molnar, D.S., Trajanovic, N., Ogilvie, R., Shapiro, C., Yan, M. and Chilcott-Tanser, L. (2006) "Sleepiness" Is Serious in Adolescence: Two Surveys of 3235 Canadian Students. BMC Public Health, 6, Article No. 116. https://doi.org/10.1186/1471-2458-6-116

[22] Mizuno, K., Okamoto-Mizuno, K. and Iwata, K. (2019) Napping Behaviors and Extracurricular Club Activities in Japanese High School Students: Associations with Daytime Sleep Problems. Clocks \& Sleep, 1, 367-384. https://doi.org/10.3390/clockssleep1030030

[23] Pavlova, M. (2017) Circadian Rhythm Sleep-Wake Disorders. Continuum, 23, 1051 1063. https://doi.org/10.1212/CON.0000000000000499

[24] Watson, A.M. (2017) Sleep and Athletic Performance. Current Sports Medicine Reports, 16, 413-418. https://doi.org/10.1249/JSR.0000000000000418

[25] Swinbourne, R., Gill, N., Vaile, J. and Smart, D. (2016) Prevalence of Poor Sleep Quality, Sleepiness and Obstructive Sleep Apnoea Risk Factors in Athletes. European Journal of Sport Science, 16, 850-858. https://doi.org/10.1080/17461391.2015.1120781

[26] Martin, T., Arnal, P.J., Hoffman, M.D. and Millet, G.Y. (2018) Sleep Habits and Strategies of Ultramarathon Runners. PLOS ONE, 13, e0194705.

https://doi.org/10.1371/journal.pone.0194705

[27] Aoki, T., Fukuda, K., Tanaka, C., Kamikawa, Y., Tsuji, N., Kasanami, R., Hara, T., Miyazaki, R., Tanaka, H., Asai, H., Yamamoto, N., Oishi, K. and Ishii, K. (2020) The Relationship between Sleep Habits, Lifestyle Factors, and Achieving GuidelineRecommended Physical Activity Levels in Ten-to-Fourteen-Year-Old Japanese Child- 
ren: A Cross-Sectional Study. PLoS ONE, 15, e0242517.

https://doi.org/10.1371/journal.pone.0242517

[28] Rozgonyi, R., Dombi, I., Janszky, J., Kovács, N. and Faludi, B. (2021) Low TestRetest Reliability of the Epworth Sleepiness Scale within a Substantial Short Time Frame. Journal of Sleep Research, e13277. https://doi.org/10.1111/jsr.13277 